\title{
O ALTO TEOR DE SILÍCIO NO SOLO INIBE O CRESCIMENTO RADICULAR DE CAFEEIROS SEM AFETAR AS TROCAS GASOSAS FOLIARES ${ }^{(1)}$
}

\author{
Rafael Vasconcelos Ribeiro ${ }^{(2)}$, Leandro da Silva ${ }^{(3)}$, Rômulo Augusto \\ Ramos $^{(3)}$, Cristiano Alberto de Andrade ${ }^{(4)}$, Fernando César Bachiega \\ Zambrosi $^{(5)}$ \& Sérgio Parreiras Pereira ${ }^{(6)}$
}

\begin{abstract}
RESUMO
O benefício do silício (Si) no crescimento de plantas cultivadas tem sido observado em vários trabalhos. O objetivo deste estudo foi avaliar os efeitos de Si no crescimento de mudas de cafeeiro cv. Catuaí Vermelho. O experimento foi conduzido em vasos, e as plantas crescidas em casa de vegetação, sem restrição hídrica. A partição de matéria seca entre raízes, caule e folhas, os teores de nutrientes e $\mathrm{Si}$ nos tecidos vegetais e no solo e as trocas gasosas foliares foram avaliados em plantas submetidas a doses de silicato de cálcio correspondentes a 0 (controle), 1,5 e $6 \mathrm{Mg} \mathrm{ha}^{-1}$. O delineamento experimental foi em blocos casualizados, com três tratamentos e 3,4 ou 18 repetições, dependendo da variável considerada. Cada parcela experimental era composta por uma planta. Em relação à altura e matéria seca total, as plantas de todos os tratamentos apresentaram desenvolvimento satisfatório, com incrementos diários compatíveis com o esperado em cafeeiros bem nutridos. Os tratamentos com silicato de cálcio causaram aumento nos teores de Ca no solo e na planta e de Si no solo. Considerando que o único nutriente alterado pelos tratamentos foi o Ca e que os teores observados na planta podem ser considerados não prejudiciais, as respostas descritas a seguir são consequência do alto teor de Si no solo. Após 130 dias do início do experimento, as plantas tratadas com $6 \mathrm{Mg} \mathrm{ha}^{-1}$ de silicato de cálcio apresentaram menor acúmulo de matéria seca nas raízes e aumento da relação entre a matéria seca da parte
\end{abstract}

\footnotetext{
(1) Recebido para publicação em julho de 2010 e aprovado em março de 2011.

(2) Pesquisador Científico, Laboratório de Fisiologia Vegetal "Coaracy M. Franco", Instituto Agronômico - IAC. Caixa Postal 28, CEP 13012-970 Campinas (SP). E-mail: rafael@iac.sp.gov.br

(3) Engenheiro-Agrônomo, Programa de Pós-graduação em Agricultura Tropical e Subtropical, IAC. E-mails: leandropg08@gmail.com; romuloiac@gmail.com

(4) Pesquisador Científico, Centro Nacional de Pesquisa de Monitoramento e Avaliação de Impacto Ambiental, Embrapa Meio Ambiente. Caixa Postal 69, CEP 13820-000 Jaguariúna (SP). E-mail: cristiano@cnpma.embrapa.br

(5) Pesquisador Científico, Centro de Pesquisa e Desenvolvimento de Solos e Recursos Ambientais, IAC. E-mail: zambrosi@iac.sp.gov.br

(6) Pesquisador Científico, Centro de Análise e Pesquisa Tecnológica do Agronegócio Café "Alcides Carvalho”, IAC. E-mail: sergiopereira@iac.sp.gov.br
} 
aérea e a do sistema radicular. Embora as plantas tenham apresentado menor crescimento radicular na maior dose de silicato de cálcio, a assimilação de $\mathrm{CO}_{2}$ e a condutância estomática não foram alteradas. Cafeeiros arábica cv. Catuaí Vermelho submetidos a alta dose de silicato de cálcio apresentam redução do crescimento radicular, porém sem comprometimento da funcionalidade e do desenvolvimento da parte aérea das plantas cultivadas sob boa disponibilidade hídrica e nutricional.

Termos de indexação: Coffea arabica, nutrição, silício, crescimento.

\title{
SUMMARY: HIGH SOIL SILICON CONCENTRATIONS INHIBIT COFFEE ROOT GROWTH WITHOUT AFFECTING LEAF GAS EXCHANGE
}

\begin{abstract}
Several studies have confirmed the benefits of silicon (Si) for crop growth. The purpose of this study was to evaluate the effects of Si on the initial growth of coffee plants cv. Catuai Vermelho. This study was carried out with potted plants grown in a greenhouse, without water deficiency. Dry matter partitioning of roots, stems and leaves as well as the chemical composition of plant tissues and soil and leaf gas exchange were evaluated in plants treated with 0 (control), 1.5 and $6 \mathrm{Mg} \mathrm{ha}^{-1}$ of calcium silicate. The experiment was arranged in a randomized block design, with three treatments, and 3, 4 or 18 replications, depending on the evaluated variable. Each plot consisted of one plant. Regarding height and total dry matter, the plant growth was satisfactory in all treatments, with daily increases similar to the expected for well-fertilized coffee plants. The treatments resulted in increased soil and plant Ca and Si concentrations. Considering that only leaf Ca concentration was affected by treatments and its concentration was not deleterious, the observed responses are consequences of the high soil Si concentrations. Root dry matter of plants treated with $6 \mathrm{Mg} \mathrm{ha}^{-1}$ of calcium silicate decreased and the ratio between shoot and root dry matter increased 130 days after the beginning of the experiment. Despite the decreases in root growth and in Ca use efficiency, leaf $\mathrm{CO}_{2}$ assimilation and stomatal conductance of the coffee plants were not affected. In summary, high soil concentrations of calcium silicate decrease the root growth of Arabica coffee plants cv. Catuai Vermelho; however, the functionality and development of shoots in well-nourished plants growing under well-watered conditions are not affected.
\end{abstract}

Index terms: Coffea arabica, nutrition, silicon, growth.

\section{INTRODUÇÃO}

Embora o silício (Si) não seja considerado um elemento essencial para a maioria das plantas, os benefícios da fertilização silicatada têm sido estudados e reconhecidos em espécies cultivadas (Richmond \& Sussman, 2003; Epstein \& Bloom, 2006; Ma \& Yamaji, 2008). O Si é um elemento que confere às plantas maior resistência a estresses bióticos e abióticos (Goto et al., 2003; Romero-Aranda et al., 2006; Hattori et al., 2007; Côté-Beaulieu et al., 2009; Savvas et al., 2009; Hashemi et al., 2010), assim como melhora o manejo fitossanitário de cafeeiros (Reis et al., 2008) e plantas de trigo (Zanão Júnior et al., 2010).

A absorção de Si ocorre por difusão passiva e também com a participação de transportadores localizados na exoderme e endoderme das raízes (Mitani \& Ma, 2005; Ma \& Yamaji, 2008), sendo o conteúdo acumulado variável de acordo com a espécie (Epstein \& Bloom, 2006; Ma \& Yamaji, 2006). Com base na relação $\mathrm{Si}: \mathrm{Ca}$, as plantas podem ser classificadas como acumuladoras, quando essa relação for maior que 1,0; intermediárias, entre 0,5 e 1,0; e não acumuladoras, quando menor que 0,5 (Ma et al., 2001). Em geral, as plantas acumulam entre 1 e $10 \%$ de Si na matéria seca (Ma \& Yamaji, 2006), e a maior parte do Si nas plantas concentra-se na parede celular, tendo função no suporte e sustentação da planta (Reis et al., 2007), podendo ser encontrado também no citoplasma das células (Heine et al., 2005). Os teores de Si nas folhas de cafeeiro variam entre 0,2 e $0,3 \%$, sendo essa espécie considerada não acumuladora (Reis et al., 2007).

O efeito benéfico do Si no acúmulo de fitomassa em plantas cultivadas está associado a alterações na estrutura das plantas, permitindo, por exemplo, a melhor captação de energia solar e redução do acamamento. Embora ainda seja desconhecida a função do Si no metabolismo vegetal (Epstein \& Bloom, 2006), postula-se que o Si solubilizado na planta tem papel na síntese de moléculas de defesa em plantas (Rodrigues et al., 2004; Ma \& Yamaji, 2008). O Si 
pode estimular o crescimento e a produção vegetal indiretamente, causando aumento no teor de clorofila nos tecidos foliares, alterando a arquitetura das plantas, tornando-as mais eretas e evitando o autossombreamento excessivo, atrasando a senescência, aumentando a rigidez estrutural dos tecidos e protegendo as plantas de agentes bióticos e abióticos (Marschner, 1995; Epstein \& Bloom, 2006; Ma \& Yamaji, 2008).

Há poucos estudos sobre os efeitos do Si no crescimento das plantas, com a maior parte das publicações tratando de aspectos nutricionais e do papel benéfico desse elemento na resistência a estresse biótico, com eventual avaliação da produtividade final do cultivo (Laviola et al., 2007; Reis et al., 2008; Pozza et al., 2009). Além desse aspecto, os efeitos benéficos do Si não são sempre constatados (Dann \& Muir, 2002). Ma \& Yamaji (2008) comentam que os efeitos benéficos do Si no crescimento vegetal são comumente verificados em plantas em condições de estresse. Todavia, há evidências de que o Si não exerce efeito sobre o acúmulo de matéria seca de Brachiaria em condição de déficit hídrico (Melo et al., 2003).

Considerando que o Brasil ocupa posição de destaque na cafeicultura mundial e a utilização de $\mathrm{Si}$ tende a ser uma prática agrícola mais comum (Reis et al., 2007), seja como corretivo de acidez dos solos (Camargo et al., 2007) ou como condicionante da produção pelo aumento da tolerância a estresses bióticos e abióticos (Ma \& Yamaji, 2008), torna-se importante aumentar a base de conhecimento sobre os efeitos do Si em cafeeiros. Nesse contexto, o objetivo deste estudo foi investigar os efeitos do Si no crescimento de cafeeiros submetidos a altas concentrações de silicato de cálcio no solo e conduzidos sob boa disponibilidade hídrica.

\section{MATERIAL E MÉTODOS}

Mudas de cafeeiro (Coffea arabica L.) cv. Catuaí Vermelho com aproximadamente seis meses de idade foram transplantadas para vasos plásticos $(20 \mathrm{~L}) \mathrm{e}$ cultivadas em casa de vegetação. Nesse ambiente, a temperatura do ar variou entre 7,4 e $39,8^{\circ} \mathrm{C}$ e as plantas foram submetidas a radiação fotossinteticamente ativa máxima de $996 \mu \mathrm{mol} \mathrm{m} \mathrm{m}^{-2} \mathrm{~s}^{-1}$. O Latossolo Vermelho-Amarelo (Embrapa, 1999) utilizado no experimento foi coletado em área de cerrado (22' $53^{\prime}$ " S; 47' 04 " O) na camada de 0 a $20 \mathrm{~cm}$ de profundidade e apresentava as seguintes características: $\mathrm{pH}\left(\mathrm{CaCl}_{2}\right)=4,3 ; \mathrm{P}=3,0 \mathrm{mg} \mathrm{dm}^{-3} ; \mathrm{S}$ $=14 \mathrm{mg} \mathrm{dm}^{-3} ; \mathrm{B}=0,3 \mathrm{mg} \mathrm{dm}{ }^{-3} ; \mathrm{Cu}=2,3 \mathrm{mg} \mathrm{dm}^{-3}$; $\mathrm{Fe}=65 \mathrm{mg} \mathrm{dm}^{-3} ; \mathrm{Mn}=3,3 \mathrm{mg} \mathrm{dm}^{-3} ; \mathrm{Zn}=0,5 \mathrm{mg} \mathrm{dm}^{-3} ;$ $\mathrm{Al}=5,0 \mathrm{mmol}_{\mathrm{c}} \mathrm{dm}^{-3} ; \mathrm{Ca}=7,0 \mathrm{mmol}_{\mathrm{c}} \mathrm{dm}^{-3} ; \mathrm{Mg}=$ $3,0 \mathrm{mmol}_{\mathrm{c}} \mathrm{dm}^{-3} ; \mathrm{K}=0,9 \mathrm{mmol}_{\mathrm{c}} \mathrm{dm}^{-3} ; \mathrm{SB}=$ $10,9 \mathrm{mmol}_{\mathrm{c}} \mathrm{dm}^{-3} ; \mathrm{CTC}(\mathrm{pH} 7,0)=49 \mathrm{mmol}_{\mathrm{c}} \mathrm{dm}^{-3} ; \mathrm{V}=$ $22 \%$; e MO $=28 \mathrm{~g} \mathrm{dm}^{-3}$ (Raij et al., 2001). As características biométricas das plantas no momento do transplantio eram: altura de $21,7 \pm 1,6 \mathrm{~cm} ; 14 \pm 1$ folhas; diâmetro de caule de 0,28 $\pm 0,04 \mathrm{~cm}$; área foliar de $261 \pm 41 \mathrm{~cm}^{2}$; e matéria seca de folhas, raízes, caule e total de $1,5 \pm 0,2 \mathrm{~g}, 0,4 \pm 0,1 \mathrm{~g}, 0,4 \pm 0,1 \mathrm{~g}$ e $2,3 \pm 0,4 \mathrm{~g}$, respectivamente. A razão entre a matéria seca da

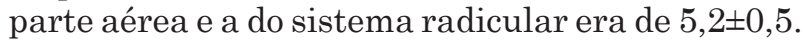

A adubação de plantio correspondeu à aplicação de $60 \mathrm{mg} \mathrm{kg}-1$ de $\mathrm{N}$ e $200 \mathrm{mg} \mathrm{kg}^{-1}$ de $\mathrm{P}$, via fosfato monoamônico (MAP), e $100 \mathrm{mg} \mathrm{kg}^{-1}$ de K na forma de cloreto de potássio $(\mathrm{KCl})$. Na mesma ocasião, calcário dolomítico foi aplicado para elevar $\mathrm{V}$ a $50 \%$, correspondendo à dose de $1 \mathrm{~g} \mathrm{~kg}^{-1}$ ou $2 \mathrm{Mg} \mathrm{ha}{ }^{-1}$. Esse procedimento foi realizado para todos os vasos, independentemente do fornecimento do silicato de cálcio, tendo em vista que o principal objetivo da adubação silicatada foi o fornecimento de Si e não a correção da acidez do solo. Antes da adubação silicatada, procedeu-se a um teste para determinar o efeito do silicato de cálcio no $\mathrm{pH}$ do solo. Após incubação de 20 dias com umidade do solo a $80 \%$ da capacidade de campo, verificou-se que a variação máxima de $\mathrm{pH}$ $\left(\mathrm{CaCl}_{2}\right)$ entre os tratamentos foi de 0,55 , o que não interferiria de forma significativa sobre outros aspectos de fertilidade do solo e nutrição das plantas, uma vez que os nutrientes foram fornecidos em quantidade suficiente. Em cobertura, procedeu-se ao fornecimento de nutrientes via fertirrigação em doses equivalentes a: $200 \mathrm{mg} \mathrm{kg}^{-1}$ de N, $120 \mathrm{mg} \mathrm{kg}^{-1}$ de K, 0,5 mg kg-1 de B, 4,7 mg kg-1 de Zn, $5 \mathrm{mg} \mathrm{kg}^{-1}$ de Mn e $1 \mathrm{mg} \mathrm{kg}^{-1}$ de $\mathrm{Cu}$. A quantidade de $\mathrm{N}$ foi aplicada em quatro vezes (a cada 15 dias), e a dos demais nutrientes, em duas vezes (a cada 15 dias).

Além do tratamento controle (sem adição de silicato de cálcio no solo), as plantas foram crescidas em solo contendo silicato de cálcio $\left(\mathrm{Ca}_{2} \mathrm{SiO}_{4}\right)$ em doses correspondentes a 1,5 e $6 \mathrm{Mg} \mathrm{ha}^{-1}$. Após o início do experimento, o solo foi mantido com umidade ao redor de $80 \%$ da capacidade de campo por um período de 130 dias. Após esse período, as plantas foram coletadas, separadas em raízes, caule e folhas e secas em estufa a $60{ }^{\circ} \mathrm{C}$ (até massa constante), sendo determinada posteriormente a matéria seca. Nesse material e no solo dos vasos, foram quantificados os teores de N, P, K, Mg, S e Ca, conforme Malavolta et al. (1997) e Raij et al. (2001). A eficiência de utilização do Ca foi calculada segundo Siddiqi \& Glass (1981) e o Si foi determinado pelo método descrito por Korndörfer et al. (2004). A altura das plantas, da base do caule até a base da gema apical, foi avaliada com régua simples. O diâmetro do caule foi medido na base do caule com paquímetro digital modelo $100.179 \mathrm{G}$ (Digimess, Brasil). A área foliar foi medida com um planímetro digital modelo LI-3100 (Licor, EUA) e as folhas com limbo foliar visível foram contadas. As trocas gasosas foram avaliadas com um analisador de gases por infravermelho modelo Li-6400 (Licor, EUA), com controle da radiação fotossinteticamente ativa e da temperatura foliar. Durante seis dias consecutivos (entre o $123^{\circ}$ e o $129^{\circ}$ dia de tratamento), medidas de assimilação de $\mathrm{CO}_{2}\left(\mathrm{P}_{\mathrm{N}}\right)$ e de condutância 
estomática $\left(g_{S}\right)$ foram realizadas em folhas completamente expandidas e localizadas na região externa (exposta) da copa das plantas. As trocas gasosas foram avaliadas entre 9 e 10h30, sob saturação luminosa (1.000 $\mu \mathrm{mol} \mathrm{m} \mathrm{m}^{-2} \mathrm{~s}^{-1}$, DaMatta et al., 2007), temperatura foliar de $24,5 \pm 2,0^{\circ} \mathrm{C}$ e diferença de pressão de vapor entre folha e ar de $1,6 \pm 0,6 \mathrm{kPa}$.

O delineamento experimental foi em blocos casualizados, com três repetições para as análises nutricionais, quatro repetições para as variáveis relacionadas ao crescimento das plantas e 18 repetições para as medidas de trocas gasosas. A causa de variação investigada foi o tratamento com silicato de cálcio, com três níveis: $0,1,5$ e $6 \mathrm{Mg} \mathrm{ha}^{-1}$. Os dados foram submetidos à análise de variância, e as médias, comparadas pelo teste de Tukey $(p<0,08)$.

\section{RESULTADOS}

A fertilização silicatada não alterou os teores de $\mathrm{P}$, $\mathrm{K}$ e $\mathrm{Mg}$ no solo, que variaram entre 99,8 e 109,0 $\mathrm{mg} \mathrm{dm}^{-3}$ de P; 4,3 e 5,2 $\mathrm{mmol}_{\mathrm{c}} \mathrm{dm}^{-3}$ de K; e 9,8 e 13,0 $\mathrm{mmol}_{\mathrm{c}} \mathrm{dm}^{-3}$ de $\mathrm{Mg}$. Por outro lado, houve aumento do teor de Ca no solo com a suplementação de silicato de cálcio (Figura 1a). O solo do tratamento com $6 \mathrm{Mg} \mathrm{ha}^{-1}$ de silicato de cálcio apresentou o maior teor de $\mathrm{Ca}$, sendo 1,8 vez maior do que o controle. Considerando os solos dos tratamentos controle e a maior dose de silicato de cálcio, houve aumento $(\mathrm{p}<0,08)$ da soma de bases $(\mathrm{SB})$ de 36,9 para $50,0 \mathrm{mmol}_{\mathrm{c}} \mathrm{dm}^{-3}$ e da saturação por bases (V) de 50,8 para $63,8 \%$, com redução da acidez potencial $(\mathrm{H}+\mathrm{Al})$ de 35,3 para $28,0 \mathrm{mmol}_{\mathrm{c}} \mathrm{dm}^{-3}$. Houve discreto aumento $(\mathrm{p}<0,08)$ no $\mathrm{pH}$ do solo, variando de 4,4 no tratamento controle a 4,7 na maior dose de silicato de cálcio. $\mathrm{O}$ fornecimento de silicato de cálcio foi efetivo em elevar a disponibilidade de Si no solo, sendo os maiores teores observados no tratamento com $6 \mathrm{Mg}^{\text {ha }}{ }^{-1}$ (Figura 1a).

Não se verificaram alterações significativas nos teores de N, P, K, Mg e S nas plantas aos 130 dias após a imposição dos tratamentos (Quadro 1). Os maiores teores de $\mathrm{P}$ foram observados nas folhas, ao passo que as raízes apresentaram os maiores teores de K (Quadro 1). O teor de Ca nas plantas mostrou sensível incremento devido à suplementação com silicato de cálcio, em especial nas folhas e raízes (Figura 1b,d). Nas folhas, o tratamento com $6 \mathrm{Mg} \mathrm{ha}^{-1}$ de silicato de cálcio induziu aumento de $40 \%$ no teor de Ca quando comparado ao controle, ao passo que o teor desse nutriente nas raízes foi aumentado em 2,4 vezes.
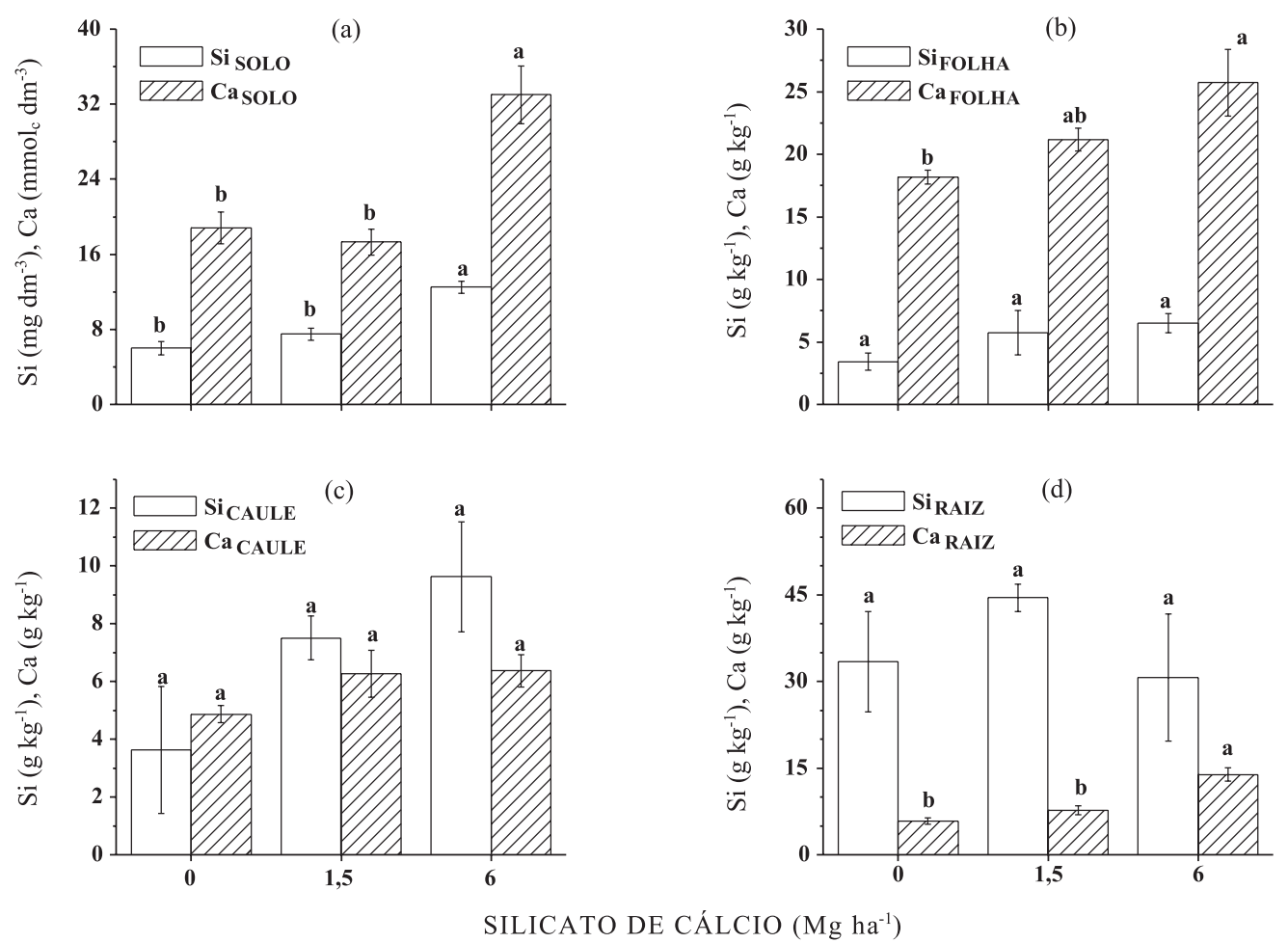

Figura 1. Variação do teor de cálcio e silício no solo (a), nas folhas (b), no caule (c) e nas raízes (d) de cafeeiros após 130 dias da adubação silicatada. Cada símbolo representa o valor médio de três (b-d) ou quatro (a) repetições ( \pm erro-padrão). Letras distintas entre tratamentos indicam diferença estatística pelo teste de Tukey $(p<0,08)$. 
Quadro 1. Efeito da adubação silicatada no teor de nitrogênio (N), potássio (K), fósforo (P), magnésio (Mg) e enxofre (S) nas frações folha, caule e raiz de cafeeiros cultivados em casa de vegetação ${ }^{(1)}$

\begin{tabular}{|c|c|c|c|c|c|c|}
\hline & $\mathrm{Ca}_{2} \mathrm{SiO}_{4}$ & $\mathbf{N}$ & $\mathbf{K}$ & $\mathbf{P}$ & $\mathrm{Mg}$ & $\mathbf{S}$ \\
\hline & $\mathrm{Mg} \mathrm{ha}^{-1}$ & & & $\mathrm{~g} \mathrm{~kg}^{-1}$ & & \\
\hline Folha & $\begin{array}{l}0 \\
1,5 \\
6\end{array}$ & $\begin{array}{l}43,3 \pm 1,0 \mathrm{a} \\
41,8 \pm 1,2 \mathrm{a} \\
44,0 \pm 0,7 \mathrm{a}\end{array}$ & $\begin{array}{l}25,4 \pm 1,1 \text { a } \\
25,4 \pm 0,2 \text { a } \\
24,7 \pm 1,2 \text { a }\end{array}$ & $\begin{array}{l}1,20 \pm 0,06 \text { a } \\
1,33 \pm 0,03 \text { a } \\
1,36 \pm 0,03 \text { a }\end{array}$ & $\begin{array}{l}5,66 \pm 0,17 \text { a } \\
5,43 \pm 0,19 \text { a } \\
5,30 \pm 0,42 \text { a }\end{array}$ & $\begin{array}{l}3,16 \pm 0,07 \text { a } \\
3,26 \pm 0,03 \text { a } \\
3,16 \pm 0,15 \text { a }\end{array}$ \\
\hline Caule & $\begin{array}{l}0 \\
1,5 \\
6\end{array}$ & $\begin{array}{l}17,7 \pm 1,5 \mathrm{a} \\
19,0 \pm 1,0 \mathrm{a} \\
18,1 \pm 0,9 \mathrm{a}\end{array}$ & $\begin{array}{l}12,4 \pm 0,3 \mathrm{a} \\
13,3 \pm 0,8 \mathrm{a} \\
12,1 \pm 0,4 \mathrm{a}\end{array}$ & $\begin{array}{l}0,53 \pm 0,03 \text { a } \\
0,66 \pm 0,12 \text { a } \\
0,60 \pm 0,00 \mathrm{a}\end{array}$ & $\begin{array}{l}2,63 \pm 0,12 \text { a } \\
3,26 \pm 0,32 \text { a } \\
2,83 \pm 0,17 \text { a }\end{array}$ & $\begin{array}{l}1,33 \pm 0,09 \text { a } \\
1,50 \pm 0,15 \text { a } \\
1,30 \pm 0,06 \text { a }\end{array}$ \\
\hline Raiz & $\begin{array}{l}0 \\
1,5 \\
6\end{array}$ & $\begin{array}{l}29,1 \pm 0,5 \mathrm{a} \\
29,5 \pm 0,3 \mathrm{a} \\
27,8 \pm 0,2 \mathrm{a}\end{array}$ & $\begin{array}{l}29,7 \pm 2,9 \mathrm{a} \\
30,2 \pm 1,9 \mathrm{a} \\
28,1 \pm 1,3 \mathrm{a}\end{array}$ & $\begin{array}{l}0,86 \pm 0,07 \quad \mathrm{a} \\
0,86 \pm 0,03 \text { a } \\
0,83 \pm 0,07 \quad \mathrm{a}\end{array}$ & $\begin{array}{l}5,83 \pm 0,38 \text { a } \\
5,86 \pm 0,15 \text { a } \\
5,83 \pm 0,15 \text { a }\end{array}$ & $\begin{array}{l}3,16 \pm 0,26 \text { a } \\
3,30 \pm 0,12 \text { a } \\
3,46 \pm 0,50 \text { a }\end{array}$ \\
\hline
\end{tabular}

(1) Avaliações realizadas 130 dias após a adubação silicatada. Médias de três repetições ( \pm erro-padrão). Em cada porção da planta, letras iguais indicam que não há diferença estatística entre as médias pelo teste de Tukey $(p=0,08)$.

Nas folhas, os cafeeiros apresentaram teores de $\mathrm{Si}$ ao redor de $6,5 \mathrm{~g} \mathrm{~kg}^{-1}$ no tratamento com $6 \mathrm{Mg} \mathrm{ha}^{-1}$, e os maiores teores absolutos de Si foram observados nas raízes, chegando a $45 \mathrm{~g} \mathrm{~kg}^{-1}$ no tratamento com $1,5 \mathrm{Mg} \mathrm{ha}^{-1}$ de silicato de cálcio (Figura $1 \mathrm{~d}$ ).

Em relação ao crescimento das plantas, a adição de silicato de cálcio não alterou o diâmetro do caule, a altura das plantas, a área foliar, a matéria seca de folha e de caule, assim como a matéria seca total das plantas (Figura 2a-e,g). A fertilização silicatada restringiu o acúmulo de matéria seca de raiz após 130 dias de tratamento (Figura 2f). Comparando as plantas controle com as submetidas ao tratamento de $6 \mathrm{Mg} \mathrm{ha}^{-1}$ de silicato de cálcio (Figura 2f), constatouse redução de $50 \%$ no crescimento radicular diário (de 23 para $11 \mathrm{mg} \mathrm{d}^{-1}$ ). Após 130 dias, o menor crescimento radicular das plantas submetidas a $6 \mathrm{Mg} \mathrm{ha}^{-1}$ de silicato de cálcio alterou a partição de matéria seca entre a parte aérea (caule+folhas) e o sistema radicular, com aumento de 4,8 (controle) para
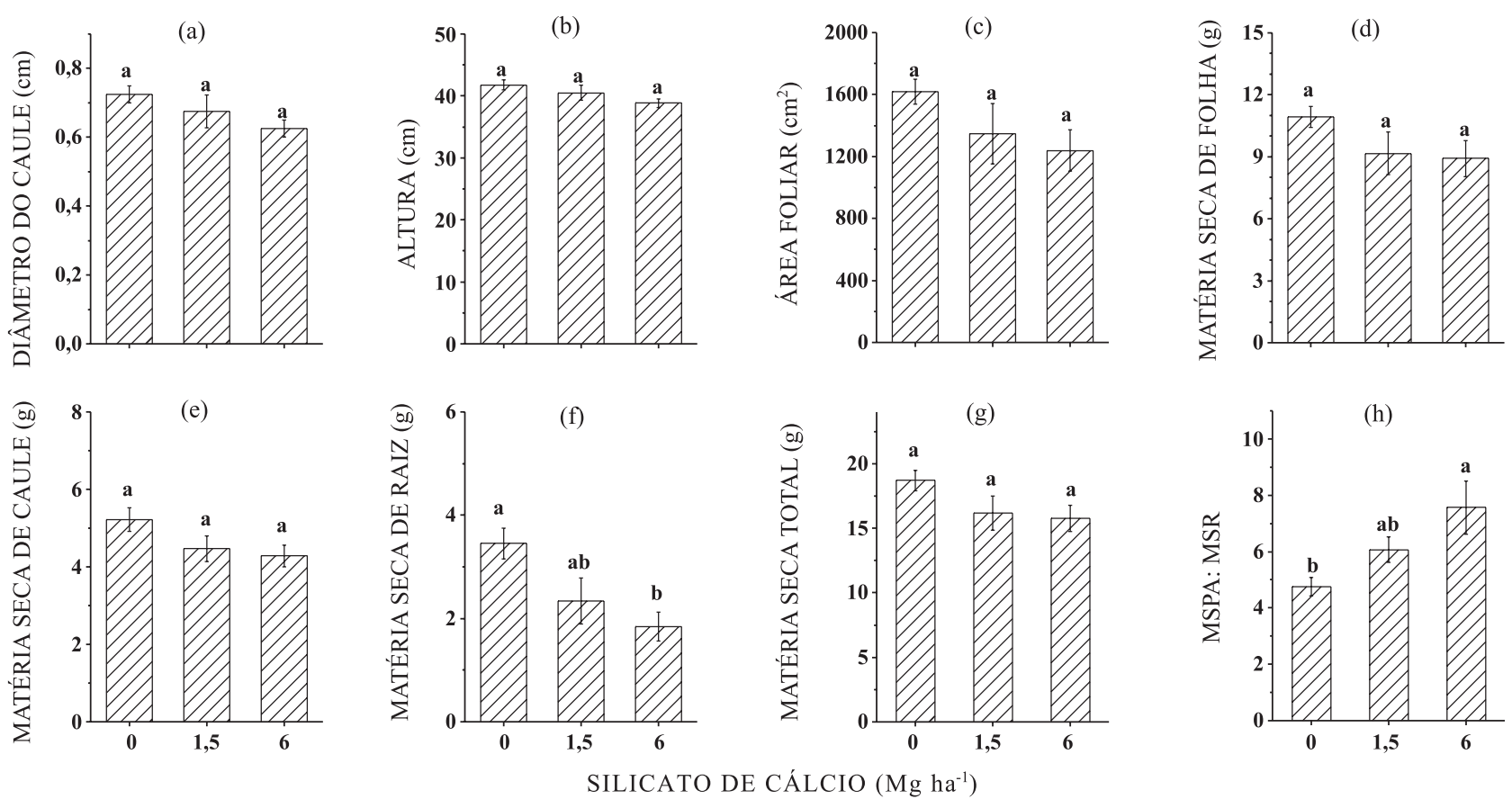

Figura 2. Diâmetro do caule (a), altura (b), área foliar (c), matéria seca de folha (d), de caule (e), de raiz (f) e total (g) e razão entre matéria de seca de parte aérea e sistema radicular (h) de cafeeiros após 130 dias da adubação silicatada. Cada histograma representa o valor médio de quatro repetições ( \pm erro-padrão). Letras distintas entre tratamentos indicam diferença estatística pelo teste de Tukey $(p<0,08)$. 
7,6 na referida razão (Figura $2 \mathrm{~h}$ ). A eficiência de utilização do Ca foi reduzida $(\mathrm{p}<0,08)$ pela adubação com $6 \mathrm{Mg} \mathrm{ha}^{-1}$ de silicato de cálcio (Figura 3). Em média, as plantas tratadas com a maior dose de silicato de cálcio apresentaram a metade da eficiência de utilização do $\mathrm{Ca}$ quando comparadas às plantas controle. Em relação às trocas gasosas, os tratamentos com silicato de cálcio não causaram variação significativa na assimilação de $\mathrm{CO}_{2}$ e na condutância estomática, com valores médios de $5 \mu \mathrm{mol} \mathrm{m}^{-2} \mathrm{~s}^{-1} \mathrm{e}$ $0,05 \mathrm{~mol} \mathrm{~m}^{-2} \mathrm{~s}^{-1}$, respectivamente (Figura 4).

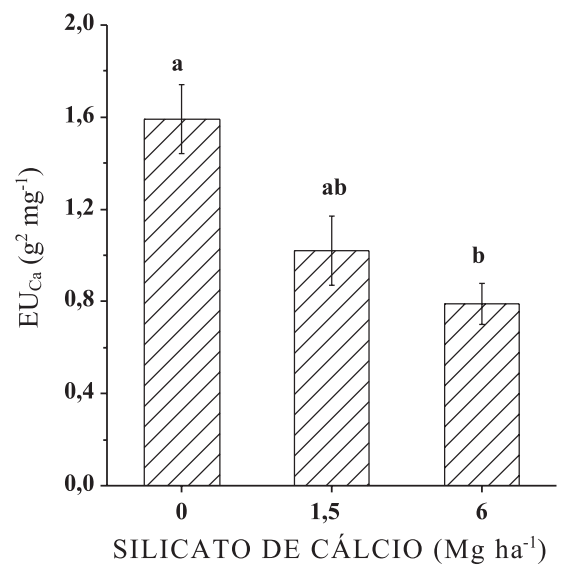

Figura 3. Eficiência de utilização do Ca de cafeeiros após 130 dias da adubação silicatada. Cada histograma representa o valor médio de três repetições ( \pm erro-padrão). Letras distintas entre tratamentos indicam diferença estatística pelo teste de Tukey $(p<0,08)$.

\section{DISCUSSÃO}

Embora haja relato de que plantas suplementadas com Si são menos afetadas por estresses de origem biótica ou abiótica e, ou, apresentam melhor desenvolvimento (Epstein, 1999; Richmond \& Sussman, 2003; Ma \& Yamaji, 2008), o presente estudo demonstra que a adubação com silicato de cálcio causou restrição no crescimento radicular dos cafeeiros em condições nutricionais e hídricas adequadas.

Em relação ao aspecto nutricional, os tratamentos não induziram resposta diferencial e o menor crescimento radicular não foi consequência de alterações na nutrição das plantas. Os teores foliares de $\mathrm{P}$ e $\mathrm{K}$ ficaram próximos ou mais elevados do que o indicado para cafeeiros jovens (Clemente et al., 2008). $\mathrm{O}$ teor foliar de $\mathrm{Mg}$ foi superior ao indicado por Malavolta (1980), e o teor de S permaneceu em torno de $3,2 \mathrm{~g} \mathrm{~kg}^{-1}$ (Quadro 1), independentemente do tratamento, estando acima do recomendado (Clemente et al., 2008). Os teores foliares de $\mathrm{N}$ foram superiores a $40 \mathrm{~g} \mathrm{~kg}^{-1}$, indicando que as folhas continham entre 1,3 e 2,2 vezes mais $\mathrm{N}$ do que o recomendado, entre 19,2 e $32,0 \mathrm{~g} \mathrm{~kg}^{-1}$ (Clemente et al., 2008), independentemente da disponibilidade de Si. Considerando os níveis de N, K, P, Mg e S (Quadro 1) e de micronutrientes (dados não apresentados), o único nutriente na planta que foi diferencialmente alterado pelos tratamentos foi o $\mathrm{Ca}$, com as plantas do tratamento com $6 \mathrm{Mg} \mathrm{ha}^{-1}$ de silicato de cálcio apresentando valores elevados nas folhas e nas raízes (Figura 1b,d). O teor de Ca nas folhas estava acima do recomendado para cafeeiros, entre 12,7 e 14,1 $\mathrm{g} \mathrm{kg}^{-1}$ (Clemente et al., 2008). As plantas controle já

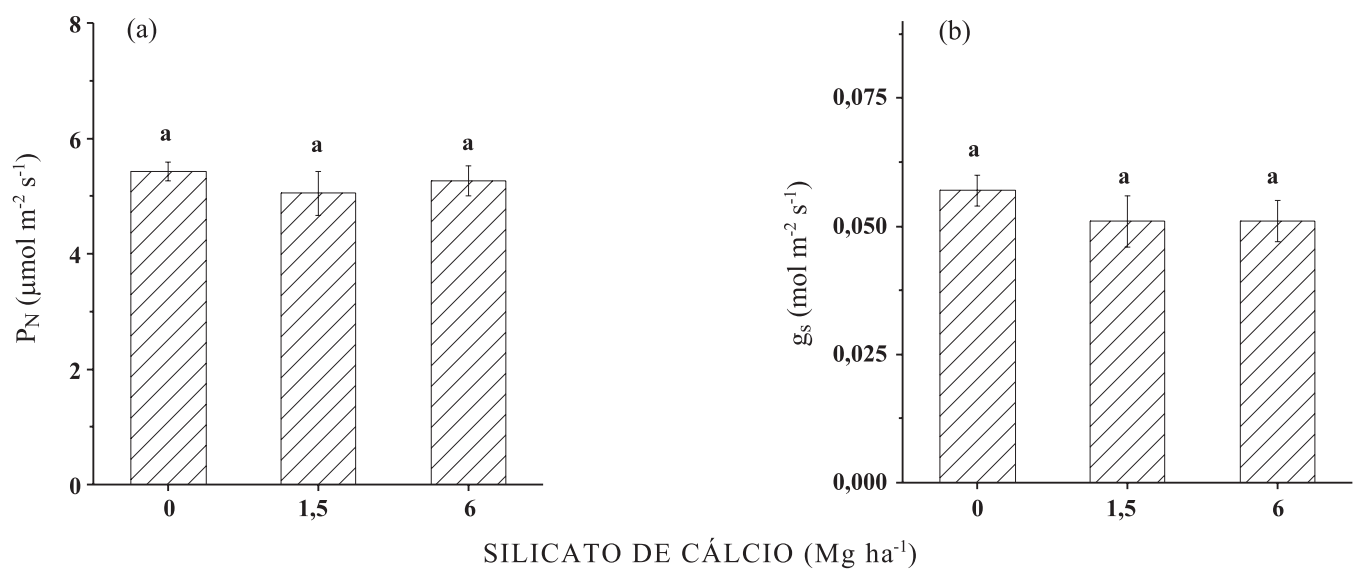

Figura 4. Assimilação de $\mathrm{CO}_{2}\left(\mathrm{P}_{\mathrm{N}}\right.$, em a) e condutância estomática $\left(\mathrm{g}_{\mathrm{S}}\right.$, em b) de cafeeiros submetidos à adubação silicatada. Condições de medida: radiação fotossinteticamente ativa de $1.000 \mu \mathrm{mol} \mathrm{m}^{-2} \mathrm{~s}^{-1}$, temperatura foliar de $24,5 \pm 2,0^{\circ} \mathrm{C}$ e diferença de pressão de vapor entre folha e ar de $1,6 \pm 0,6 \mathrm{kPa}$. Cada histograma representa o valor médio de 18 repetições ( \pm erro-padrão). Letras iguais entre tratamentos indicam semelhança estatística pelo teste de Tukey $(p>0,08)$. 
apresentavam teores de Ca nas folhas acima do recomendado ( $\left.18 \mathrm{~g} \mathrm{~kg}^{-1}\right)$, sendo esse aspecto intensificado com a fertilização silicatada. Comparando o teor foliar de $\mathrm{Ca}$ das plantas submetidas ao tratamento com $6 \mathrm{Mg} \mathrm{ha}^{-1}$ de silicato de cálcio com o limite inferior recomendado por Clemente et al. (2008), nota-se um teor cerca de duas vezes maior nas plantas tratadas (Figura $1 \mathrm{~b}$ ).

Como o Ca é um nutriente constituinte da parede celular e altera a resistência desta à extensão (Marschner, 1995), poder-se-ia sugerir que a elevação do conteúdo de Ca observada nas raízes das plantas tratadas com silicato de cálcio induziria maior resistência à deformação da parede celular, o que explicaria a restrição no crescimento. Todavia, os níveis de $\mathrm{Ca}$ nos tecidos foliares, caule e raízes observados na maior dose de silicato de cálcio são compatíveis com os reportados por Rodrigues et al. (2006) e Mattiello et al. (2008), quando não houve comprometimento do desenvolvimento das plantas. Teores foliares de Ca entre 6 e $16 \mathrm{~g} \mathrm{~kg}^{-1}$ foram observados por Laviola et al. (2007) em plantas adultas durante a fase de formação dos frutos, sugerindo mais uma vez que os teores observados nas plantas desse estudo estavam elevados (> $\left.18 \mathrm{~g} \mathrm{~kg}^{-1}\right)$ e não eram limitantes.

Teores elevados de Ca no citossol poderiam levar à precipitação de proteínas, dentre as quais as enzimas envolvidas no metabolismo de carbono (Marschner, 1995). Nesse contexto, torna-se importante considerar que as folhas são fontes de fotoassimilados para o desenvolvimento das raízes e que alterações no metabolismo da fonte devem afetar a disponibilidade de energia e carbono para o crescimento dos drenos no caso, as raízes (DaMatta et al., 2007). Entretanto, o possível efeito da alta concentração de Ca foliar na fotossíntese pode ser descartado, uma vez que não foram observadas diferenças na assimilação de $\mathrm{CO}_{2}$ com a variação da disponibilidade de silicato de cálcio (Figura 4a). Os valores de assimilação de $\mathrm{CO}_{2} \mathrm{e}$ condutância estomática relatados neste estudo são provas do bom estado fisiológico das plantas (Konrad et al., 2005; DaMatta et al., 2007), indicando que a limitação do crescimento radicular em condições hídricas e nutricionais adequadas não comprometeu o metabolismo vegetal.

Em estudo sobre a nutrição de cafeeiros em resposta à aplicação de silicato de cálcio, Pozza et al. (2009) relataram que a eficiência de utilização do Ca não foi alterada com doses de até $2 \mathrm{Mg} \mathrm{ha}^{-1}$, variando entre 1,14 e 1,61 $\mathrm{g}^{2} \mathrm{mg}^{-1}$, independentemente da dose de silicato de cálcio. Esses valores estão próximos dos observados neste estudo em plantas controle $\left(\sim 1,59 \mathrm{~g}^{2} \mathrm{mg}^{-1}\right)$ e bem superiores aos das plantas submetidas ao tratamento com silicato de cálcio (Figura 3). Embora a eficiência de utilização do Ca das plantas submetidas a $6 \mathrm{Mg} \mathrm{ha}^{-1}$ tenha sido significativamente reduzida, o valor está próximo a 0,76 $\mathrm{g}^{2} \mathrm{mg}^{-1}$, reportado por Tomaz et al. (2003) em plantas com bom desenvolvimento. De qualquer forma, a menor eficiência das plantas do tratamento com $6 \mathrm{Mg} \mathrm{ha}^{-1}$ (Figura 3) foi ocasionada pela menor produção de matéria seca de raízes e concentração mais elevada de $\mathrm{Ca}$ no tecido vegetal (Figura 2f). Essa resposta é esperada, visto que aumentos na absorção e acúmulo de nutrientes não são acompanhados na mesma proporção por ganhos de matéria seca pelas plantas (Marschner, 1995).

Em relação ao silício, Botelho et al. (2009) relataram recentemente a redução da fotossíntese potencial em cafeeiros adubados com alta dose de ácido silícico. Embora não haja diferença estatística entre os teores de Si nas folhas dos cafeeiros (Figura 1b), as folhas do tratamento com $6 \mathrm{Mg} \mathrm{ha}^{-1}$ tinham ao redor de $6,5 \mathrm{~g} \mathrm{~kg}^{-1}$ de $\mathrm{Si}(0,65 \%)$. Do ponto de vista biológico, a diferença de 1,9 vez no teor de Si foliar entre as plantas controle e as submetidas a $6 \mathrm{Mg} \mathrm{ha}^{-1}$ poderia induzir alguma resposta fisiológica. No entanto, essa hipótese também não é aplicável a esse estudo, uma vez que a fotossíntese das plantas foi semelhante entre os tratamentos (Figura 4a).

Em geral, os cafeeiros não mostraram acúmulo de Si na parte aérea e a relação $\mathrm{Si}$ Ca foliar inferior a 1 confirma a pressuposição do cafeeiro como uma espécie não acumuladora de Si (Ma et al., 2001; Reis et al., 2007). A baixa capacidade de acumular Si está relacionada à absorção e transporte desse elemento na planta, sendo possivelmente uma consequência da ausência ou pequena presença dos transportadores Lsi1 (do solo para a raiz) e Lsi2 (da raiz para o xilema) nas células das raízes (Nikolic et al., 2007; Yamaji \& Ma, 2007; Ma \& Yamaji, 2008). A maior presença de Si nas raízes quando comparadas aos demais tecidos e a similaridade dos teores de Si nas raízes entre os tratamentos (Figura 1) sugerem que a atividade dos transportadores é baixa e que o processo de absorção/ transporte ocorre predominantemente por difusão passiva, como constatado em tomateiros (Mitani \& $\mathrm{Ma}, 2005)$.

Como a maior parte do Si na raiz é constituinte da parede celular (Heine et al., 2005) e a lignificação e suberização são aumentadas com a presença de Si (Fleck et al., 2010), uma provável explicação para o menor crescimento radicular seria a ocorrência de alterações nas características mecânicas que afetam a expansão celular (Hattori et al., 2003). Essa suposição pode ser descartada, uma vez que os teores de Si nas raízes foram semelhantes entre os tratamentos controle e com $6 \mathrm{Mg} \mathrm{ha}^{-1}$ de silicato de cálcio (Figura 1). Corroborando esse raciocínio, Sonobe et al. (2011) reportaram a ausência de alterações anatômicas nas características radiculares ligadas ao transporte de água em plantas de sorgo submetidas à aplicação de Si.

Rena \& DaMatta (2002) afirmam que excelente produtividade de cafeeiros é observada em $\mathrm{pH}$ próximo de 5,0. No tratamento com maior redução na matéria seca das raízes (6 $\mathrm{Mg} \mathrm{ha}^{-1}$ de silicato de cálcio) o pH 
do solo foi de 4,7. Logo, o baixo $\mathrm{pH}$ do solo (entre 4,3 e $4,7)$ não poderia ser considerado limitante. Argumentação no sentido de que houve restrição do crescimento radicular devido ao cultivo em vaso seria plausível, porém os vasos utilizados (20 L) tinham solo suficiente para suportar o crescimento inicial dos cafeeiros durante 130 dias. Ainda, as taxas de crescimento em altura e em massa seca são compatíveis com as observadas na literatura (Nazareno et al., 2003; Silva et al., 2004). De fato, o crescimento em altura das plantas foi de aproximadamente $2,8 \mathrm{~mm} \mathrm{~d}^{-1}$, independentemente da aplicação de silicato de cálcio. Esse valor está próximo ao máximo crescimento relatado por DaMatta et al. (1999) em cafeeiro arábica $\left(\sim 2,2 \mathrm{~mm} \mathrm{~d}^{-1}\right)$. Em cafeeiro arábica, durante a fase de crescimento ativo, o crescimento dos ramos foi de aproximadamente $1,5 \mathrm{~mm} \mathrm{~d}^{-1}$ (Silva et al., 2004), valor inferior ao observado neste estudo. Logo, os cafeeiros no presente estudo apresentaram bom crescimento em altura. Já o acúmulo de matéria seca das folhas variou entre 57 e $72 \mathrm{mg} \mathrm{d}^{-1} \mathrm{e}$, considerando que essa porção representava mais de $50 \%$ da massa seca total das plantas, o acúmulo de matéria seca total também não foi alterado, variando entre $104 \mathrm{e} 126 \mathrm{mg} \mathrm{d}^{-1}$.

$\mathrm{O}$ desbalanço na partição de matéria seca entre a parte aérea e as raízes em condições de boa disponibilidade de recursos não trouxe consequências para o crescimento geral da planta, dado pelo acúmulo de matéria seca total (Figura 2g). O contrário pode ocorrer em ambientes com variação significativa da disponibilidade de água, nos quais uma copa bem desenvolvida demandaria maior quantidade de água para suportar a evapotranspiração da cultura. O mesmo seria válido em ambientes com limitação nutricional, onde as plantas com sistema radicular limitado teriam dificuldade em manter o estado nutricional em níveis adequados.

Os resultados do presente estudo evidenciam a necessidade de pesquisas com outras fontes de silício, cujos benefícios para a agricultura são relatados nos mais diversos cultivos e ambientes (Epstein, 1999; Richmond \& Sussman, 2003; Epstein \& Bloom, 2006; Liang et al., 2007; Ma \& Yamaji, 2008), assim como estudos que visem entender e esclarecer as possíveis interações físicas e químicas diretas ou indiretas entre o Si no solo e as raízes de cafeeiros jovens. A maior parte dos estudos que comprovam os benefícios do $\mathrm{Si}$ na agricultura foi realizada com espécies herbáceas de rápido crescimento (Goto et al., 2003; RomeroAranda et al., 2006; Hattori et al., 2007; Côté-Beaulieu et al., 2009; Savvas et al., 2009; Hashemi et al., 2010; Zanão Júnior et al., 2010). O hábito de crescimento lento em espécies arbóreas, como o cafeeiro, ou rápido em espécies herbáceas, como o arroz - parece ser um fator adicional que altera a resposta ao $\mathrm{Si}$, sendo o benefício mais evidente nas espécies anuais. Outro ponto que deve ser considerado diz respeito à variação genotípica em uma mesma espécie (Ma \& Yamaji, 2008; Tahir et al., 2010), sendo a resposta ao Si diferencial entre as cultivares de cafeeiro (Reis et al., 2007; Pozza et al., 2009). Variações na proporção entre raízes laterais e adventícias poderiam ser responsáveis pela absorção diferencial de Si entre cultivares de cafeeiro, pois sabe-se que os transportadores Lsi1 estão preferencialmente localizados nas raízes laterais (Yamaji \& Ma, 2007).

\section{CONCLUSÃO}

Cafeeiros arábica cv. Catuaí Vermelho submetidos a alta dose de silicato de cálcio apresentam redução do crescimento radicular, porém sem comprometimento da funcionalidade e do desenvolvimento da parte aérea das plantas cultivadas sob boa disponibilidade hídrica e suprimento adequado de nutrientes.

\section{AGRADECIMENTOS}

Os autores agradecem ao Consórcio Pesquisa Café (Brasil), pelo financiamento da pesquisa (proc. $\mathrm{n}^{\circ}$ 19.2004.137.04), e à Fundação de Amparo a Pesquisa do Estado de São Paulo (Fapesp, SP, Brasil) e ao Conselho Nacional de Desenvolvimento Científico e Tecnológico (CNPq, Brasil), pelas bolsas de pós-graduação (L.S., proc. $\left.\mathrm{n}^{\circ} 2008 / 52411-6\right)$ e de produtividade em pesquisa (R.V.R., proc. $\mathrm{n}^{\circ}$ 303998/2008-3).

\section{LITERATURA CITADA}

BOTELHO, D.M.S.; POZZA, E.A.; ALVES, E.; FURTINI NETO, A.E.; BARBOSA, J.P.R.A.D. \& CASTRO, D.M. Aspectos anatômicos e fisiológicos de mudas de cafeeiro (Coffea arabica L.) com cercosporiose (Cercospora coffeicola Berk. \& Cook.) adubadas com ácido silícico. Coffee Sci., 4:93-99, 2009.

CAMARGO, M.S.; KORNDÖRFER, G.H. \& PEREIRA, H.S. Solubilidade do silício em solos: Influência do calcário e ácido silícico aplicados. Bragantia, 66:637-647, 2007.

CLEMENTE, F.M.V.T.; CARVALHO, J.G.; GUIMARÃES, R.J. \& MENDES, A.N.G. Faixas críticas de teores foliares de macronutrientes no cafeeiro em pós-plantio - primeiro ano. Coffee Sci., 3:47-57, 2008.

CÔTÉ-BEAUlieU, C.; CHAIN, F.; MEINZIES, J.G.; KINRADE, S.D. \& BÉLANGER, R.R. Absorption of aqueous inorganic and organic silicon compounds by wheat and their effect on growth and powdery mildew control. Environ. Exper. Bot., 65:155-161, 2009.

DAMATTA, F.M.; AMARAL, J.A. \& RENA, A.B. Growth periodicity in trees of Coffea arabica L. in relation to nitrogen supply and nitrate reductase activity. Field Crops Res., 60:223-229, 1999. 
DAMATTA, F.M.; RONCHI, C.P.; MAESTRI, M. \& BARROS, R.S. Ecophysiology of coffee growth and production. Braz. J. Plant Physiol., 19:485-510, 2007.

DANN, E.K. \& MUIR, S. Peas growth in media with elevated plant-available silicon levels have higher activities of chitinase and $\hat{a}-1,3$ glucanase, are less susceptible to a fungal leaf spot pathogen and accumulate more foliar silicon. Austr. Plant Pathol., 31:9-13, 2002.

EMPRESA BRASILEIRA DE PESQUISA AGROPECUÁRIA EMBRAPA. Centro Nacional de Pesquisa do Solo. Sistema brasileira de classificação de solos. Rio de Janeiro, 1999. $412 \mathrm{p}$.

EPSTEIN, E. Silicon. Ann. Rev. Plant Physiol. Plant Molec. Biol., 50:641-664, 1999.

EPSTEIN, E. \& BLOOM, A. Nutrição mineral de plantas: Princípios e perspectivas. Londrina, Planta, 2006. 403p.

FLECK, A.T.; NYE, T.; REPENNING, C.; STAHL, F.; ZAHN, M. \& SCHENK, M.K. Silicon enhances suberization and lignification in roots of rice (Oryza sativa). J. Exper. Bot., 2010. doi:10.1093/jxb/erq392. Acesso em 16/02/2011.

GOTO, M.; EHARA, H.; KARITA, S.; TAKABE, K.; OGAWA, N.; YAMADA, Y.; OGAWA, S.; YAHAYA, M.S. \& MORITA, O. Protective effect of silicon on phenolic biosynthesis and ultraviolet spectral stress in rice crop. Plant Sci., 164:349-356, 2003.

HASHEMI, A.; ABDOLZADEH, A. \& SADEGHIPOUR, H.R. Beneficial effects of silicon nutrition in alleviating salinity stress in hydroponically grown canola, Brassica napus L., plants. Soil Sci. Plant Nutr., 56:244-253, 2010.

HATTORI, T.; INANAGA, S.; TANIMOTO, E.; LUX, A.; LUXOVÁ, M. \& SUGIMOTO, Y. Silicon-induced changes in viscoelastic properties of sorghum root cell walls. Plant Cell Physiol., 44:743-749, 2003.

HATTORI, T.; SONOBE, K.; INANAGA, S.; AN, P.; TSUJI, W.; ARAKI, H.; ENEJI, A.E. \& MORITA, S. Short term stomatal responses to light intensity changes and osmotic stress in sorghum seedlings raised with and without silicon. Environ. Exper. Bot., 60:177-182, 2007.

HEINE, G.; TIKUM, G. \& HORST, W.J. Silicon nutrition of tomato and bitter gourd with special emphasis on silicon distribution in root fractions. J. Plant Nutr. Soil Sci., 168:600-606, 2005

KONRAD, M.L.F.; SILVA, J.A.B.; FURLANI, P.R. \& MACHADO, E.C. Trocas gasosas e fluorescência da clorofila em seis cultivares de cafeeiro sob estresse de alumínio. Bragantia, 64:339-347, 2005.

KORNDÖRFER, G.H.; PEREIRA, H.S. \& NOLLA, A. Análise de silício: solo, planta e fertilizante. Uberlândia, GPSi/ ICIAG/UFU, 2004. 50p. (Boletim Técnico, 2)

LAVIOLA, B.G.; MARTINEZ, H.E.P.; SOUZA, R.B. \& ALVAREZ V., V.H. Dinâmica de cálcio e magnésio em folhas e frutos de Coffea arabica. R. Bras. Ci. Solo, 31:319329, 2007.
LIANG, Y.; SUN, W.; ZHU, Y. \& CHRISTIE, P. Mechanisms of silicon-mediated alleviation of abiotic stress in higher plants: A review. Environ. Poll., 147:422-428, 2007.

MA, J.F.; MIYAKE, Y. \& TAKAHASHI, E. Silicon as a beneficial element for crop plant. In: DATNOFF, L.E.; SNYDER, G.H. \& KORNDÖRFER, G.H., eds. Silicon in agriculture. Amsterdam, Elsevier, 2001. p.17-39.

MA, J.F. \& YAMAJI, N. Silicon uptake and accumulation in higher plants. Trends Plant Sci., 11:392-397, 2006.

MA, J.F. \& YAMAJI, N. Functions and transport of silicon in plants. Cel. Molec. Life Sci., 65:3049-3057, 2008.

MALAVOLTA, E. Elementos de nutrição mineral de plantas. São Paulo, Ceres, 1980. 253p.

MALAVOLTA, E.; VITTI, C.G. \& OLIVEIRA, S.A. Avaliação do estado nutricional das plantas: Princípios e aplicações. Piracicaba, Associação Brasileira para Pesquisa da Potassa, 1997. 319p.

MARSCHNER, H. Mineral nutrition of higher plants. London, Academic Press, 1995. 920p.

MATTIELLO, E.M.; PEREIRA, M.G.; ZONTA, E.; MAURI, J.; MATIELLO, J.D.; MEIRELES, P.G. \& SILVA, I.R. Produção de matéria seca, crescimento radicular e absorção de cálcio, fósforo e alumínio por Coffea canephora e Coffea arabica sob influência da atividade do alumínio em solução. R. Bras. Ci. Solo, 32:425-434, 2008.

MELO, S.P.; KORNDÖRFER, G.H.; KORNDÖRFER, C.M.; LANA, R.M.Q. \& SANTANA, D.G. Silicon accumulation and water deficit tolerance in Brachiaria grasses. Sci. Agric., 60:755-759, 2003.

MITANI, N. \& MA, J.F. Uptake system of silicon in different plant species. J. Exper. Bot., 56:1255-1261, 2005.

NAZARENO, R.B.; OLIVEIRA, C.A.S.; SANZONOWICZ, C.; SAMPAIO, J.B.R.; SILVA, J.C.P. \& GUERRA, F.A. Crescimento inicial do cafeeiro Rubi em resposta a doses de nitrogênio, fósforo e potássio e a regimes hídricos. Pesq. Agropec. Bras., 38:903-910, 2003.

NIKOLIC, M.; NIKOLIC, N.; LIANG, Y.; KIRKBY, E.A. \& RÖMHELD, V. Germanium-68 as an adequate tracer for silicon transport in plants. Characterization of silicon uptake in different crop species. Plant Physiol., 143:495503, 2007.

POZZA, A.A.A.; CARVALHO, J.G.; GUIMARÃES, P.T.G.; FIGUEIREDO, F.C. \& ARAÚJO, A.R. Suprimento do silicato de cálcio e a eficiência nutricional de variedades de cafeeiro. R. Bras. Ci. Solo, 33:1705-1714, 2009.

RAIJ, B.van; ANDRADE, J.C.; CANTARELLA, H. \& QUAGGIO, J.A. Análise química para avaliação da fertilidade de solos tropicais. Campinas, Instituto Agronômico, 2001. 284p.

REIS, T.H.P.; GUIMARÃES, P.T.G.; FIGUEIREDO, F.C.; POZZA, A.A.A.; NOGUEIRA, F.D. \& RODRIGUES, C.R. O silício na nutrição e defesa de plantas. Belo Horizonte, Epamig, 2007. 120p. (Boletim Técnico, 82) 
REIS, T.H.P.; FIGUEIREDO, F.C.; GUIMARÃES, P.T.G.; BOTREL, P.P. \& RODRIGUES, C.R. Efeito da associação silício líquido solúvel com fungicida no controle fitossanitário do cafeeiro. Coffee Sci., 3:76-80, 2008.

RENA, A.B. \& DAMATTA, F.M. O sistema radicular do cafeeiro: Morfologia e ecofisiologia. In: ZAMBOLIM, L., ed. O estado da arte de tecnologias na produção de café. Viçosa, MG, Universidade Federal de Viçosa, 2002. p.11-92.

RICHMOND, K.E. \& SUSSMAN, M. Got silicon? The nonessential beneficial plant nutrient. Cur. Opin. Plant Biol., 6:268-272, 2003.

RODRIGUES, F.A.; MCNALLY, D.J.; DATNOFF, L.E.; JONES, J.B.; LABBÉ, C.; BENHAMOU, N.; MENZIES, J.G. \& BÉLANGER, R.R. Silicon enhances the accumulation of diterpenoid phytoalexins in rice: A potential mechanism for blast resistance. Phytopathology, 94:177-183, 2004.

RODRIGUES, L.A.; MARTINEZ, H.E.P.; NEVES, J.C.L.; NOVAIS, R.F. \& MENDONÇA, S.M. Respostas nutricionais de cafeeiros catuaí e icatu a doses de calcário em subsuperfície. R. Bras. Ci. Solo, 30:985-995, 2006.

ROMERO-ARANDA, M.R.; JURADO, O. \& CUARTERO, J. Silicon alleviates the deleterious salt effect on tomato plant growth by improving plant water status. J. Plant Physiol., 163:847-855, 2006.

SAVVAS, D.; GIOTIS, D.; CHATZIEUSTRATIOU, E.; BAKEA, M. \& PATAKIOUTAS, G. Silicon supply in soilless cultivations of zucchini alleviates stress induced by salinity and powdery mildew infections. Environ. Exper. Bot., 65:11-17, 2009.
SIDDIQI, M.Y. \& GLASS, A.D.M. Utilization index: A modified approach to the estimation and comparison of nutrient utilization efficiency in plants. J. Plant Nutr., 4:289-302, 1981.

SILVA, E.A.; DAMATTA F.M.; DUCATTI C.; REGAZZI A.J. \& BARROS, R.S. Seasonal changes in vegetative growth and photosynthesis of Arabica coffee trees. Field Crops Res., 89:349-357, 2004.

SONOBE, K.; HATTORI, T.; AN, P.; TSUJI, W.; ENEJI, A.E.; KOBAYASHI, S.; KAWAMURA, Y.; TANAKA, K. \& INANAGA, S. Effect of silicon application on sorghum root responses to water stress. J. Plant Nutr., 34:71-82, 2011.

TAHIR, M.A.; RAHMATULLAH; AZIZ, T. \& ASHRAF, M. Wheat genotypes differed significantly in their response to silicon nutrition under salinity stress. J. Plant Nutr., 33:1658-1671, 2010.

TOMAZ, M.A.; SILVA, S.R.; SAKIYAMA, N.S. \& MARTINEZ, H.E.P. Eficiência de absorção, translocação e uso de cálcio, magnésio e enxofre por mudas enxertadas de Coffea arabica. R. Bras. Ci. Solo, 27:885-892, 2003.

YAMAJI, N. \& MA, J.F. Spatial distribution and temporal variation of the rice silicon transporter Lsi1. Plant Physiol., 143:1306-1313, 2007.

ZANÃO JÚNIOR, L.A.; FONTES, R.L.F.; COELHO, P.H.M.; KORNDÖRFER, G.H. \& ZAMBOLIM, L. Soil-applied silicon decreases severity of wheat spot blotch on silicondeficient soils. R. Bras. Ci. Solo, 34:401-408, 2010. 